\title{
Analysis of the Value of Brand Equity from the Perspective of Consumer Psychology
}

\author{
Lintong Jiao \\ School of Psychology, Nanjing Normal University, Nanjing, China \\ Email: jiaolintongpsy@163.com
}

How to cite this paper: Jiao, L.T. (2018) Analysis of the Value of Brand Equity from the Perspective of Consumer Psychology. Open Journal of Social Sciences, 6, 68-75. https://doi.org/10.4236/jss.2018.612007

Received: November 19, 2018

Accepted: December 14, 2018

Published: December 17, 2018

Copyright $\odot 2018$ by author and Scientific Research Publishing Inc. This work is licensed under the Creative Commons Attribution International License (CC BY 4.0).

http://creativecommons.org/licenses/by/4.0/

\begin{abstract}
Brand equity is an important object of study in the field of marketing and consumer psychology. This paper proceeds from the three constituent elements of brand equity, and taking "Xiang Piao Piao" brand as an example, expounds the role of these factors such as brand awareness, perceived quality, brand preferences resulting from consumer subjective factors in enhancing the value of brand equity. Combining the information from "Xiang Piao Piao Foods Co., Ltd. initial public offering of shares and listing prospectus" published by China Securities Regulatory Commission, this paper analyzes the important role of brand equity for promoting the development of enterprise.
\end{abstract}

\section{Keywords}

Brand Equity, Brand Awareness, Brand Perceived Quality, Brand Preference

\section{Introduction}

In recent years, brand equity has received attention in the field of consumer psychology. This may be related to the further development of the market economy and the rise of the new consumer group with younger generation as major member pursuing a personalized consumer experience. It is the appeal of more and more enterprises to analyze the constituent elements of brand equity and find ways to improve the value of brand equity. This paper analyzes the constituent elements of brand equity from the perspective of consumer psychology, and taking "Xiang Piao Piao" brand as an example, combining business management data with the subjective perception of consumers, analyzes the important role of the value of brand equity in enterprise development. 


\section{Literature Reviews}

\subsection{The Definition of Brand Equity}

How to define brand equity? Different scholars give different answers from the perspective of different disciplines such as economics, marketing, and psychology. This article focuses on the definition of brand equity from the psychological perspective. H.S. Huang and D.L. Peng believe that brand equity is the consumer's knowledge of the brand. It has the following three characteristics: first, the brand equity is intangible; second, the brand equity is brought by the brand name; third, the value of the brand to the enterprise is generated by the influence of the brand on the consumer [1]. This definition is proposed by two scholars who compared the views of relevant scholars at home and abroad, widely recognized by domestic academic circles. This article uses this definition.

\subsection{Constituent Elements of Brand Equity}

J.Y. Ding believes that brand awareness, brand perceived quality, brand association (relevance) and brand loyalty are important sources of brand equity value. Spreding activation theory was proposed by psychologists Collins and Loftus [2]. This theory means that human memory is composed of knowledge, and knowledge is represented by a network of nodes and connections between nodes. Based on the definition that brand equity is the consumer's knowledge of the brand, H.S. Huang and D.L. Peng combine the spreding activation theory, propose that the elements of brand equity are essentially the association between the brand name and other nodes [3]. David. A. Aaker considers that the 11 concept nodes associated with the brand name are product attribute, product evaluation, customer benefit, relative price, application or use, user or customer, celebrity or ordinary people, lifestyle or personality, product category, competitor and country or region [4]. H.S. Huang and D.L. Peng summarizes these 11 concept nodes into three categories: product category, product evaluation and related product. Brand name and the association of these three categories are what they consider to be the constituent elements of the brand equity.

It can be seen that the association between product category and brand name is equivalent to the concept of brand awareness that J.Y. Ding believes; the association between brand name and product evaluation is brand perceived quality; the association between brand name and related category is based on each person's experience and subjective preferences, this association can be called brand preference. Such as the consumer's preference for the image spokesperson of the brand, the appreciation or disgust of the packaging style of the brand product or even the individual's impression of the country which the brand belongs to, and other subjective factors lead to very personal brand preferences. Regarding to brand loyalty, we believe that brand loyalty is the product of the positive association between brand name and the three categories mentioned above. It is the result of the formation of brand equity rather than the constituent elements of brand equity. Combining the above two viewpoints, we propose the following 
constituent elements of brand equity: brand awareness, perceived quality, and brand preferences resulting from consumer subjective factors.

\section{Constituent Elements of Brand Equity of "Xiang Piao Piao"}

"Xiang Piao Piao" is the cup-packed milk tea brand created by Xiang Piao Piao Foods Co., Ltd. At present, "Xiang Piao Piao" occupies the largest cup-packed milk tea market in China. In 2012, it was awarded the "China Well-known Trademark" by the State Administration for Industry and Commerce. Xiang Piao Piao Foods Co., Ltd. approved for listing by China Securities Regulatory Commission. Unless special note, the operating data of Xiang Piao Piao Food Co., Ltd. quoted in this article comes from the paper called "Xiang Piao Piao Foods Co., Ltd. initial public offering of shares and listing prospectus" published on the official website of the China Securities Regulatory Commission [5]. This paper analyzes the reasons for the formation of "Xiang Piao Piao" brand equity from three aspects: brand awareness, brand perceived quality and brand preference resulting from consumer subjective factors. At the same time, explores the impact of three constituent elements on the value of brand equity.

\subsection{Brand Awareness of "Xiang Piao Piao"}

The association strength of brand name and product category reflects brand awareness, which is "brand awareness" at the group measurement level [1]. "Xiang Piao Piao" is a brand name that suggests brand type. It fits well with the product characteristics of the cup-packed milk tea. Studies have shown that the semantic and phonological characteristics of brand names can lead to changes in consumers' perceptions and preferences of brands. If the semantic characteristics of the brand name are strongly related to the characteristics of the product or service, the consumer will have a more positive attitude towards the brand and a stronger willingness to purchase [6] [7]. The semantic characteristic of "Xiang Piao Piao" is closely related to the mellow product characteristic of cup-packed milk tea. In terms of phonological characteristics, J. Sun and H.X. Zhang believes that Compared to non-repeated two-syllable brand name, the repeated two-syllable brand name will make consumers feel that the brand is more like a baby, then feel that the brand is warmer, but the ability is lower [8]. The effect of repeated two-syllable name on product preferences is regulated by product type: for hedonic products, consumers prefer the repeated two-syllable brand name; for practical products, consumers prefer non-repeated two-syllable brand name [9]. For "Xiang Piao Piao", the brand name of instant cup-packed milk tea products, the name of the repeated two-syllable enhances the warmth of the brand, and as a hedonic product, it also makes consumers more preferred. In summary, from the semantic and phonological, "Xiang Piao Piao" perfectly fits the characteristics of its products, laying a solid foundation for high brand awareness and high brand equity value.

In addition, in the marketing strategy, "Xiang Piao Piao" takes a "focus, con- 
centration" brand strategy. Since its establishment in 2005, Xiang Piao Piao Foods Co., Ltd. has positioned itself as a "milk tea expert". Different from the strategy of major competitors producing multiple foods, beverage products and operating multiple brands, The company has long been focusing on the cup-packed milk tea segment of market, focusing on creating "Xiang Piao Piao" milk tea brand, which has strong brand awareness in the field of cup-packed milk tea.

Xiang Piao Piao Foods Co., Ltd. has established a three-dimensional, all-round market impact management system. All along, product sales are mainly offline dealers, supplemented by online e-commerce platform. The company sells products to dealers by the way of buy-out sales. Dealers sell products to distributors and terminal sales channels, and ultimately consumers buy products through terminal sales channels and e-commerce platforms.

In 2014-2016, the proportion of sales to dealers was $99.92 \%, 99.62 \%$ and 99.24\%, which were the company's most important sales methods. The company mainly sells through distribution channels and directly targets dealers, which helps dealers to further expand sales network channels. The implementation of buyout sales for dealers has increased the enthusiasm of dealer sales. The wide range of sales channels and the strong marketing incentives of dealers have greatly contributed to the improvement of product awareness.

At the same time, the expansion of online channels is undoubtedly important for the promotion of brand awareness. It can be seen from the "Announcement of Business Data for the First Three Quarters of 2018", which published by Xiang Piao Piao Foods Co., Ltd. [10], although the overall sales revenue of the e-commerce channel is not as good as the dealer channel, online sales revenue increased by $140.89 \%$ year-on-year, growing faster than traditional channels. How to do online platform sales in the era of mobile Internet and expand the brand's awareness are challenges that enterprises must face.

The company has produced well-known advertisements such as "drink milk tea, drink 'Xiang Piao Piao' only”; “Xiang Piao Piao', the pioneer of cup-packed milk tea, leading sales for eight consecutive years"; "the cups of 'Xiang Piao Piao' can be connected around the earth for 3 laps"; "when you feel a little of hungry and a little of sleepy, you can drink 'Xiang Piao Piao"'. Promoting through the TV stations such as Hunan Satellite TV, Zhejiang Satellite TV, Jiangsu Satellite TV, and online media such as Youku, Aiqiyi, Tencent Video, etc., brought $59.50 \%$ market share in the 2016 cup-packed milk tea market segment and expanded the brand's awareness. In the future, the company needs to adapt to the development of the times, consider expanding its promotion channels of We media.

\subsection{Brand Perceived Quality of "Xiang Piao Piao"}

Brand perceived quality depends on the association between brand name and brand evaluation. If the promotion of brand awareness is the credit of the corporate marketing department, the guarantee of brand perception quality de- 
pends on the production department. Consumers' perceived quality that is good and consistent with expectations is an important guarantee for brand equity. The company has established a strict quality and safety control system, strictly complying with product quality testing measures in the aspects of supplier acceptance review, procurement, production, and product inspection.

The company attaches great importance to brand image and adheres to the principle of quality first, actively adopts and draws on domestic and international advanced food safety and quality management methods to continuously improve product quality.

Depending on its high-quality products and services, "Xiang Piao Piao" fulfills its product positioning of "healthy milk tea" and establishes a good perceived quality in the minds of consumers.

\subsection{Brand Preference Resulting from Consumer Subjective Factors of "Xiang Piao Piao"}

Although the constituent element of brand preference resulting from consumer subjective factors is strongly correlation with consumer's subjective preferences and personal life experiences, companies can still improve brand equity by catering to consumer preferences.

"Xiang Piao Piao" focus on creating a warm and sweet brand experience, the candidates for their image spokespersons not only meet this trait requirement, but also cater to the development of the times and the needs of consumers. From the "heartthrob" Hao Chen, who loved by 80s, to Hanliang Zhong and Weiting Chen, who were obsessed by 90 s and 00 s, closely followed the preferences of major consumer groups.

In addition, the packaging also transforms from a single warm style to a warm and simple packaging style, which is also adapted to most of the 90s' and 00s' preference.

In terms of network platform, the style of the "Xiang Piao Piao" flagship store will also change with the current hotspots. For example, the company decorated the store with the phenomenon-level network elective program "Chinise hip-hop" elements. then it was replaced by a sweet and sweet Mid-Autumn theme dress during the Mid-Autumn Festival.

The company's initiatives are all in line with the preferences of mainstream consumers at the time. This approach is beneficial to this domestically produced young brand, enhances its brand equity, stays alive and is free from elimination in the torrent of the market economy when the company only owns single product and was full of competitors around.

\section{Brand Equity and Development of Corporate}

Since the establishment of Xiang Piao Piao Foods Co., Ltd. in August 2005, the brand of "Xiang Piao Piao" has been born. When seeing the market potential of "Xiang Piao Piao", the company was not eager to capture the market, but to 
conduct small-scale trial sales first. During this period, each sales point has a special person to track the sales of milk tea and the customer's experience, then recorded in detail, finally got a unified analysis from the company to optimize the business. In this way, the cup-packed milk tea "Xiang Piao Piao" is accepted by the public because of its convenience. Once it was launched, it was very popular and leaded the new direction of the development of the milk tea industry [11]. The brand awareness of "Xiang Piao Piao" has started, which has laid a solid foundation for the formation of its brand equity.

Brand loyalty refers to consumers' satisfaction, love and belief in the brand. It is the core of brand marketing, a measure of customers' trust and dependence on brands, it is also an important indicator of the value of brand equity. Brand loyalty mainly includes cognitive loyalty, emotional loyalty and behavioral or intentional loyalty. Brand equity management pays more attention to the loyalty of consumer behavior, that is, the customer's long-term repeated purchase of the brand's products, especially in the face of the temptation of competitive brands in terms of price, etc., also willing to buy and pay a higher price for the brand [12]. In the face of strong competitors, the "Xiang Piao Piao" brand has also gone through a detour. The company has transformed its "focus, concentration" brand strategy, was involved in liquid milk tea, other convenience foods and even other industries. With the increase in product categories, the development of its core product-cup-packed milk tea, has been suppressed, sales have declined, market share has decreased, consumers have lost loyalty to the brand. The transition has encountered bottlenecks. After a period of exploration, the company, with the help of professional consulting companies, has strengthened the brand strategy of "focus, concentration", which has taken root in the cup-packed milk tea market and regained the favor of consumers.

As the pioneer of cup-packed milk tea, the company has been deeply cultivating the beverage sub-sector industry for many years, paying attention to the research and development of the taste, craft and quality of milk tea products, enhancing the competitiveness of products and exploring the development direction of the milk tea industry. The company formulates the technical standard of the milk tea industry, plays an important role in the development of the industry. In the cup-packed milk tea sub-sector industry, the market share of "Xiang Piao Piao" brand has remained at the first place for a long time. From 2014 to 2016, the market share of "Xiang Piao Piao" is 59.50\%, 56.4\%, 57.00\% respectively. It can be seen that the brand loyalty, especially the consumer behavior loyalty of "Xiang Piao Piao" is quite high.

In summary, we can see that the development of the company has always been closely linked to its brand strategy. The development of the enterprise will certainly facilitate the improvement of brand equity, but the development of the enterprise is inseparable from the vast market and rich profits brought by the brand equity. Enterprises need to enhance brand awareness, brand perception quality and brand preference resulting from consumer subjective factors by clearing brand strategy, innovative marketing model, and understanding con- 
sumer demand, thereby to enhance the value of brand equity of enterprises.

\section{Conclusion}

Through the case analysis of the "Xiang Piao Piao" brand, this paper further clarifies the specific presentation of the three constituent elements of brand equity in business practice. At the same time, from the perspective of consumer psychology, this paper provides reference paths for enterprises to start to enhance the value of brand equity from these three factors.

\section{Suggestions and Prospects}

Although the "Xiang Piao Piao" brand has brought huge benefits to the company, it should actively explore the possibilities of brand extension when the company is in an external environment with high competitive pressure and rapid changes in consumer preferences; in an internal environment with high cost of advertising marketing and dealer management. In view of the problems of single product structure and insufficient of innovation in the company, it is recommended to use the brand equity and cohesive effects acquired by the "Xiang Piao Piao" brand to continuously enhance the popularity of existing products in the market, then extends to other milk tea categories.

In the future, based on the existing brand equity, the company can further explore the consumption potential of cup-packed milk tea through innovativing formula research and development, producing health and advanced milk tea, guiding consumption habits. It also can vigorously expand the market demand for liquid milk tea, pure natural milk tea, create a healthy and original brand awareness quality to expand the consumer group and enhance the brand loyalty of the original consumers. "Xiang Piao Piao" will be the classic and benchmark brand in Chinese milk tea industry, and will promote milk tea into the mainstream drinking market all over the world.

There are some conflicts between brand extension and brand strategy of "focus, concentration". How to deal with the problem of "degree" of brand extension? How can we extend the new consumer groups and develop new products without affecting the perceived quality of the brand in the segmentation field? In the following research on brand equity, we can discuss these issues. Otherwise, this article lacks empirical data from consumer perspective.

In future researches, we can conduct empirical research on the subjective perception of consumers' constituent elements of brand equity, and provide more favorable support for the brand equity value improvement path.

\section{Acknowledgements}

Thanks to all who have helped with the writing of this article.

\section{Conflicts of Interest}

The author declares no conflicts of interest regarding the publication of this paper. 


\section{References}

[1] Huang, H.S. and Peng, D.L. (2002) A Cognitive Model of Brand Equity. Advances in Psychological Science, 10, 350-359.

[2] Ding, J.Y. (2013) Applying Psychological Technology to Enhance Brand Equity Value. Psychology: Techniques and Applications, No. 2, 35-37.

[3] Collins, A.M. and Loftus, E.F. (1988) A Spreading-Activation Theory of Semantic Processing. Readings in Cognitive Science, 82, 126-136. https://doi.org/10.1016/B978-1-4832-1446-7.50015-7

[4] Aaker, D.A. (2006) Manage Brand Equity: Capitalizing on the Value of a Brand Name. China Machine Press, Beijing.

[5] China Securities Regulatory Commission (2017) Xiang Piao Piao Foods Co., Ltd. initial Public Offering of Shares and Listing Prospectus. http://www.csrc.gov.cn/pub/zjhpublic/G00306202/201704/t20170420_315496.htm

[6] Keller, K.L., Heckler, S.E. and Houston, M.J. (1998) The Effects of Brand Name Suggestiveness on Advertising Recall. Journal of Marketing, 62, 48-57. https://doi.org/10.1177/002224299806200105

[7] Lee, Y.H. and Ang, K.S. (2003) Brand Name Suggestiveness: A Chinese Language Perspective. International Journal of Research in Marketing, 20, 323-335. https://doi.org/10.1016/j.ijresmar.2003.03.002

[8] Sun, J. and Zhang, H.X. (2012) The Effect of Brand Name Suggestiveness on Consumer Decision Making: The Moderating Roles of Consumer Need for Cognition and Expertise. Acta Psychologica Sinica, 44, 698-710.

[9] Wei, H., Wang, T., Zhou, Z.K., et al. (2016) The Effect of Repeated Two-Syllable Brand Name on Consumer's Perception and Preference. Acta Psychologica Sinica, 48, 1479-1488. https://doi.org/10.3724/SP.J.1041.2016.01479

[10] Xiang Piao Piao Foods Co., Ltd. (2018) Xiang Piao Piao Foods Co., Ltd. Announcement of Business Data for the First Three Quarters of 2018. http://www.sse.com.cn/disclosure/listedinfo/announcement/c/2018-1023/603711_2 0181023_1.pdf

[11] Song, Z.P. (2017) Xiang Piao Piao: Creating Cup-Packed Milk Tea Myth. Business China, No. 8, 72-77.

[12] Ding, J.Y. (2006) The Composition and Value of Brand Equity. Commercial Times, No. 27, 29-30. 